\title{
Self-potential inversion for the permeability and streaming current coefficient using the rock physical empirical law
}

\author{
Yusuke OZAKI $^{1,2}$, Hitoshi MIKADA ${ }^{1}$, Tada-nori GOTO ${ }^{1}$ and Junichi TAKEKAWA ${ }^{1}$ \\ ${ }^{1}$ Dept. of Civil and Earth Res. Eng., Kyoto University \\ ${ }^{2}$ JSPS Research Fellow
}

\begin{abstract}
In this study, we extended our 2D inversion program that estimate the permeability structure from Self-potential (SP) profile to include the equation describing the permeability and streaming current coefficient. The SP is affected by the permeability, streaming current coupling coefficient and resistivity. Recently, the equation that describes the relationship between permeability and streaming current has been proposed and this equation is independent on the kind of soil or rock. We use this equation for our inversion and improve to our scheme. We apply our scheme to the synthetic SP profile and compare the inversion result considered the relationship to one ignored the relationship. Our inversion results show the difference in the inversion image, especially the value of estimated permeability. From this result, consideration of the relationship between permeability and streaming current coefficient is necessary for the accurate analysis of SP profile.
\end{abstract}

\section{INTRODUCTION}

Self-potential or streaming potential (SP) method is one of geophysical methods expected to be useful for the estimation of groundwater flow system because the SP is mainly generated by the groundwater flow. Recently, several methods have been developed to transform the SP profile to parameters related to the groundwater flow; for example, water head (e.g., Jardani et al., 2009), permeability (e.g., Revil and Jardani, 2009), permeability structure (Ozaki et al., 2013), etc., quantitatively.

The SP is affected by the permeability, streaming current coefficient and resistivity. This multi parameter problem makes the SP analysis difficult. Among these parameters, the resistivity structure can be estimated by other geophysical method, for example, electrical resistivity tomography or electrical magnetism method. We assume that we use the estimated resistivity structure by these methods during the analysis of SP profile.

Both the permeability anomaly and the streaming current coefficient generate the source of SP and affect the SP profile (Ozaki et al., 2010). These two parameters are related because they share same factors that compose each parameter (Lorne et al., 1999). This suggests that the change of streaming current coefficient due to the change of permeability must be taken into account during the estimation of permeability structure from SP profile.
Recently, the equation describing the relationship between permeability and streaming current coefficient has been proposed (e.g., Jougnot et al., 2012). This equation enables the quantitative analysis of SP considering the relationship between parameters because any kinds of soil or rock satisfy this equation under the condition that the resistivity of pore water is same.

In this study, we extended our inversion code for the estimation of permeability structure to include the equation. Our inversion modifies the permeability and streaming current coefficient simultaneously. We compare the inversion results considered the relationship and not considered one.

\section{THEORY AND METHOD}

The governing equation of the groundwater flow in saturated zone is derived from the Darcy's law and the mass conservation equation as:

$$
\mathbf{q}=-\nabla(K \nabla h)
$$

where $\mathbf{q}$ is the external source of groundwater flow $\left[\mathrm{S}^{-1}\right], \mathrm{K}$ is permeability $\left[\mathrm{m} \mathrm{s}^{-1}\right]$ and $\mathrm{h}$ is water head $[\mathrm{m}]$. When the source of electrical current is only the groundwater flow, the total subsurface electrical current is descrived with the conduction current and convection current as:

$$
\mathbf{i}=-\sigma \nabla \varphi-L \nabla h
$$


where $\mathbf{i}$ is total electrical current $\left[\mathrm{A} \mathrm{m}^{-2}\right], \sigma$ is electrical conductivity $\left[\mathrm{S} \mathrm{m} \mathrm{m}^{-1}\right], \varphi$ is electrical potential $[\mathrm{V}]$ and $\mathrm{L}$ is streaming curent co-efficitnt $\left[\mathrm{A} \mathrm{m}^{-2}\right]$. The mass conservation of equation(2) is satisfied 0 . Then, the water head and electrical potential is related as

$$
\begin{aligned}
\nabla(\sigma(\nabla \varphi)) & =-\nabla L \cdot \nabla h+L \nabla^{2} h \\
& =-\nabla L \cdot \nabla h+L \nabla \log (K) \nabla h
\end{aligned}
$$

The first term of left side is the source of SP due to the change of streaming current coefficient and the second term is the source due to the change of permeability.

The finite element modelling substitutes the differential equation(1) and equation(3) for the matrix and vector forms as:

$$
\begin{gathered}
F_{1}(K) H=Q(K) \\
F_{2}(\sigma) \Phi=-F_{3}(L) H
\end{gathered}
$$

,where $F_{1}, F_{2}$ and $F_{3}$ are matrices driven from the right side of equation (1), left side and right side of equation (3) respectively, $\mathrm{H}$ is the water head vector, $\mathrm{Q}$ is the vector of external source of groundwater flow and $\Phi$ is the electrical potential vector.

We defined the objective function $\mathrm{U}$ according to the Tikhonov regularizarion. The objective functions $\mathrm{U}$ are minimized by the permeability $\mathrm{K}$ for the inversion. The SP is related with the permeability from equarion (4) and (5) as:

$$
\Phi=-F_{2}(\sigma)^{-1} F_{3}(L) F_{1}^{-1}(K) Q(K) .
$$

The objective function is described as:

$U=\| \Phi_{o b s}-\left(-F_{2}(\sigma)^{-1} F_{3}(L) F_{1}^{-1}(K) Q(K)\left\|^{2}+\lambda\right\| C \mathbf{m} \|^{2}(7)\right.$

where $\Phi_{\text {obs }}$ is observed SP profile, $\lambda$ is hyper-parameter, $\mathrm{C}$ is the matrix of smoothness constrain and $\mathbf{m}$ is $\log 10(\mathrm{~K})$. In this study, we use the equation that describes the relationship between the permeability and streaming current coefficient. In this case, the Jacobian of the $\Phi$ becomes as:

$$
\frac{\partial \Phi}{\partial k}=-F(\sigma)^{-1} \frac{\partial F(L)}{\partial L} \frac{d L}{d k}-F(\sigma)^{-1} F(L) \frac{d H}{d k}
$$

We use the equation (8) to modify the permeability structure and estimate the permeability and streaming current coefficient simultaneously.

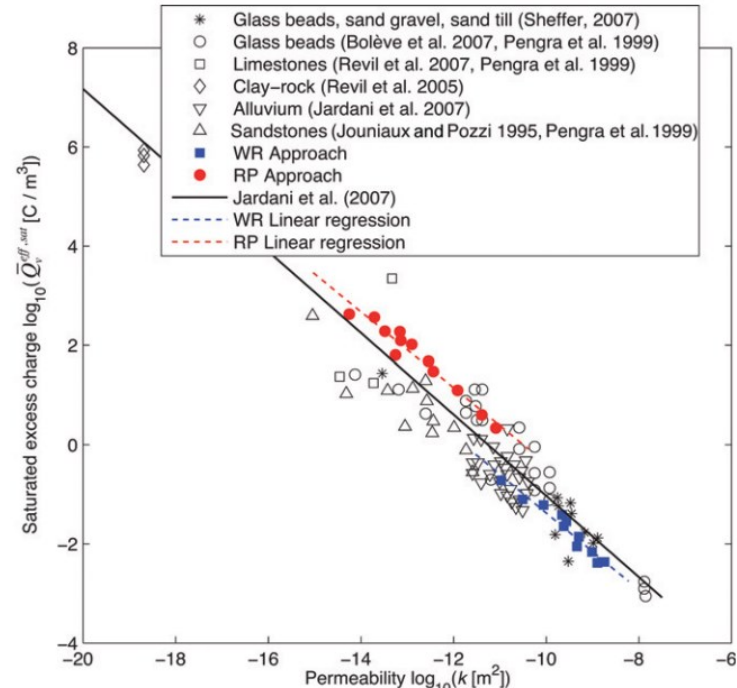

Figure 1 The graph of relationship between permeability and excess charge from Jougnot et al., (2012). The shape of points in graph show the kind of soil or rock. The red and blue line show the theoretical relationship calculated by Jougnot et al., (2012)

\section{PERMEABILITY AND STREAMING CURRENT COEFFICITNT}

In this study, we use the relationship between permeability and streaming current coefficient. In this section, we introduce the relationship between these two parameters. The permeability $\mathrm{k}\left[\mathrm{m}^{2}\right]$ and the streaming current coefficient are related to each other by the following empirical law and the theoretical equation.

$$
\begin{gathered}
\log \left(Q_{v}\right)=-9.2849-0.8219 \log (k) \\
K=\frac{k \rho g}{\mu_{w}} \\
L=K Q_{v}
\end{gathered}
$$

where $Q_{v}\left[\mathrm{C} \mathrm{m}^{-3}\right]$ is the charge density per unit pore volume, $\mu_{\mathrm{w}}[\mathrm{Pa} \mathrm{s}]$ is the dynamic water content, $\rho$ $\left[\mathrm{kg} \mathrm{m}^{-3}\right]$ is the density of water and $\mathrm{g}\left[\mathrm{m} \mathrm{s}^{-2}\right]$ is the gravitational acceleration (Jardani et al., 2009; Revil and Leroy, 2004).

Recently, Jougnot et al.,(2012) solve the diffusion of ion, the electrical potential and water flow in the pore space with two different approach theoretically to described the $\mathrm{Q}_{\mathrm{v}}$ as a function of permeability, water saturation, porosity, etc. They estimate the relationship of $\mathrm{Q}_{\mathrm{v}}$ and permeability as:

$$
\begin{aligned}
& \log \left(Q_{v}\right)=-9.14-0.77 \log (k) \\
& \log \left(Q_{v}\right)=-8.01-0.76 \log (k)
\end{aligned}
$$


These empirical relationship and theoretical relationship are shown in Figure1. These theoretical relationships correspond to the empirical one. From this feature, both theoretical and empirical relationships between permeability and streaming current coefficient are reliable to use the SP analysis. The streaming current coefficient increases as the permeability become high according to this relationship. The SP sources due to the change of permeability itself and due to the change of streaming current coefficient following the change of permeability are opposite according to the equation (3), (8), (9) and (10). However, the change of streaming current coefficient is much smaller than the change of permeability. According to the equations (3), (8), (9) and (10), the source due to the change of water pressure is 5 times larger than the source due to the charge of streaming current coefficient in 1D case. From this consideration, the permeability anomaly is main factor of SP anomaly.

\section{SYNTHETIC SP PROFILE}

In this study, we calculate the SP profile and invert the calculated SP profile as the observed data. Figure 2 shows the subsurface model for the calculation of SP profile. We locate the vertical low permeability zone and horizontal high permeability zone. The parameters are shown at Table 1 and streaming current coefficient is calculated from the permeability and Equations (8), (9) and (10). Figure 3 is the calculated SP profile. Two peaks at the horizontal distance of $220 \mathrm{~m}$ and $480 \mathrm{~m}$ are due to

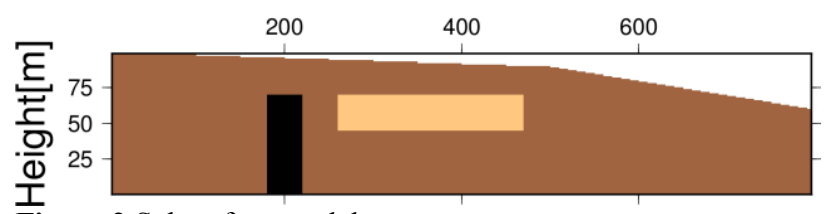

Figure 2 Subsurface model

Table 1 Parameters for the simulation

\begin{tabular}{|c|c|c|c|}
\hline & $\mathrm{K}[\mathrm{m} / \mathrm{s}]$ & $\mathrm{L}\left[\mathrm{A} / \mathrm{m}^{2}\right]$ & $\sigma[\mathrm{S} / \mathrm{m}]$ \\
\hline Background & $1 \times 10^{-6}$ & $1.19 \times 10^{-5}$ & 0.01 \\
\hline $\begin{array}{c}\text { High } \\
\text { permeability }\end{array}$ & $1 \times 10^{-4}$ & $4.34 \times 10^{-5}$ & 0.1 \\
\hline $\begin{array}{c}\text { Low } \\
\text { permeability }\end{array}$ & $1 \times 10^{-8}$ & $8.42 \times 10^{-6}$ & 0.001 \\
\hline
\end{tabular}

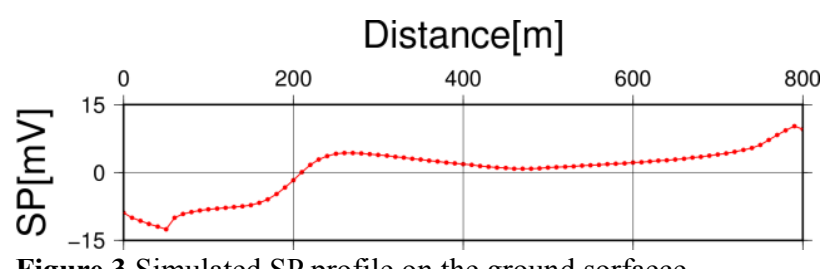

Figure 3 Simulated SP profile on the ground sorfaece. the subsurface high permeability anomaly. The drastic increase of SP at the horizontal distance of $200 \mathrm{~m}$ is due to the vertical low permeability anomaly. We use this simulated data as an observed data and try to reconstruct the permeability structure of given model.

\section{SENSITIVITY OF INVERSION}

Figure 4 shows the sensitivity of permeability to the surface SP profile when subsurface permeability structure is uniform. In this case, the sensitivity considering the change of streaming current coefficient and without consideration of it are similar. Figure 5 shows the sensitivity when the subsurface structure includes the permeability anomaly. The horizontal high permeability of $1 \times 10^{-5}$ is located at the center of the model. The streaming current coefficient of background and subsurface anomaly are calculated with equations (8), (9) and (10). In this case, the sensitivity under the permeability anomaly becomes low about 1 order when the effect of change of streaming current coefficient is considered. Such difference of sensitivity would make the different subsurface image of permeability structure after several

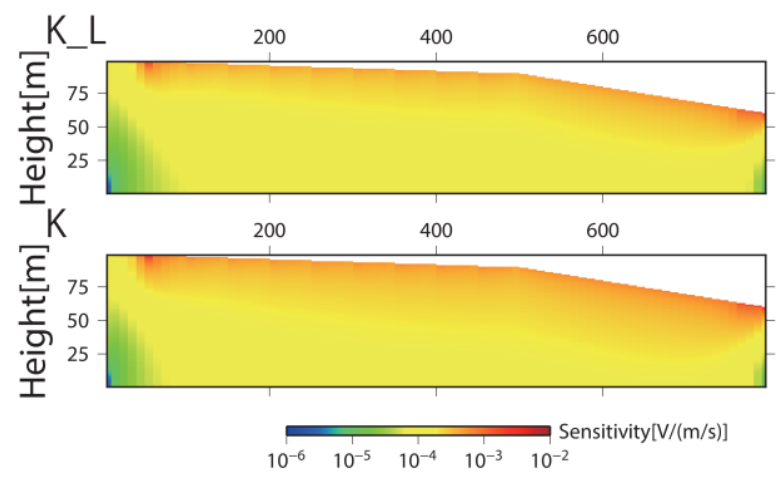

Figure 4 Comparison of sensitivity. The top picture shows the sensitivity considering the relationship between permeability and streaming current coefficient. The bottom picture shows the sensitivity ignoring the relationship between permeability and streaming current coefficient.

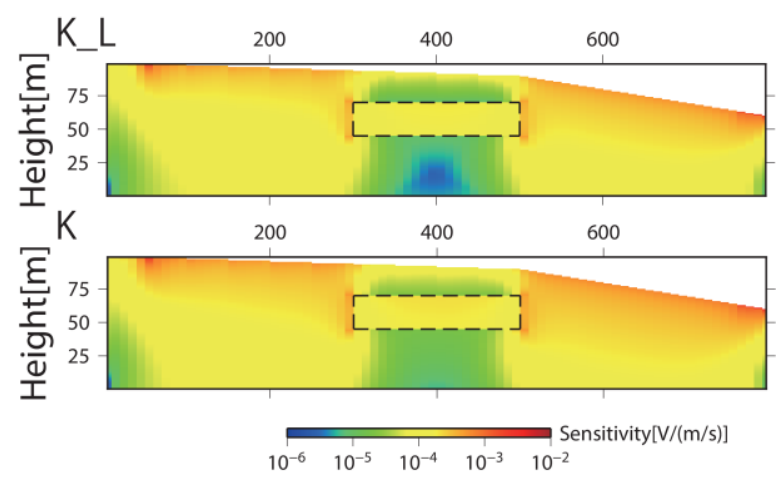

Figure 5 Comparison of sensitivity when the subsurface structure includes the permeability anomaly. The dashed lines show the location of permeability anomaly. 


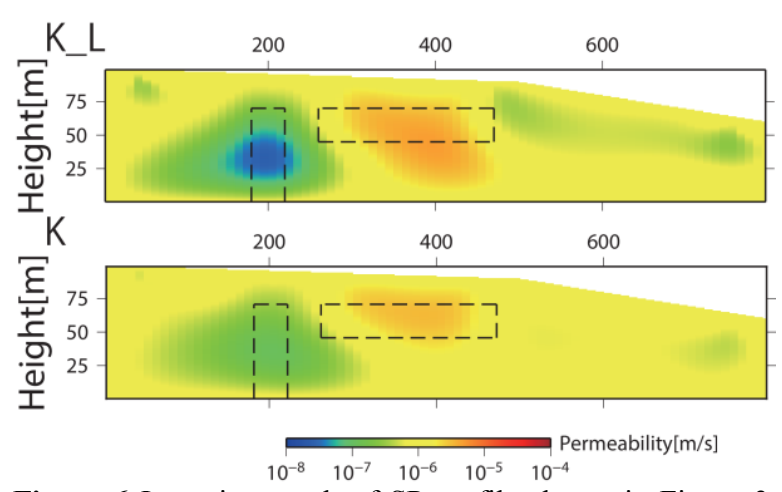

Figure 6 Inversion result of SP profile shown in Figure 3. The top picture shows the inversion result considering the relationship between permeability and streaming current coefficient. The bottom picture shows the inversion result ignoring the relationship. The dashed lines show the exact location of permeability.

iterations of inversion.

\section{INVERSION RESULT}

Figure 6shows the inversion result of SP profile shown in Figure 3. When we consider the change of streaming current coupling coefficient, the estimated permeability anomaly become lower and higher than the other case. The stronger contract between background and permeability anomaly appear around the exact location of permeability than the inversion result ignoring the relationship between permeability and streaming current coefficient. In addition, artifact from the horizontal distance of $500 \mathrm{~m}$ to $800 \mathrm{~m}$ also appears. The high permeability zone is constructed deeper area than the exact location of permeability when the relationship is considered. On the other hand, the estimated high permeability zone with the inversion ignoring the relationship appears only shallow area. The difference of sensitivity under the high permeability anomaly causes this difference.

\section{CONCLUSION}

In this study, we developed the inversion code including the change of coupling coefficient due to the change of permeability. We conclude that:

- The permeability and streaming current coefficient is connected by the simple equation. This equation is reliable and useful for the quantitative analysis of SP analysis.

- The sensitivity of permeability to the SP profile differs on whether the relationship is considered or not, especially around the permeability anomaly.

- The contrast between background and estimated permeability anomaly is especially affected by the change of streaming current coefficient due to the change of permeability.

The consideration of the change of streaming current coefficient is necessary to estimate the permeability anomaly accurately. In addition, other factors, for example, the effect of unsaturated zone on the SP, would be needed to be considered for the accurate analysis of SP profile.

ACKNOWLEDGMENT: This work was supported by JSPS KAKENHI Grant number 243701. We are grateful for the financial support from Japan Society for the Promotion of Science (JSPS).

\section{REFERENCES}

1) Jardani A., Revil A., Barrash W., Crespy A., Rizzo E., Straface S., Cardiff M., Malama B., Miller C. and Johnson T. (2009): Reconstruction of the Water Table from Self-Potential Data: A Bayesian Approach, GROUND WATER, 47,213-227.

2) Jougnot D., Linde, N, Revil A., and Doussan C. (2012): Derivation of Soil-Specific Streaming Potential Electrical Parameters from Hydrodynamic Characteristics of Partially Saturated Soils: Vadose Zone J., 11, 1, doi: 10.2136/vzj2011.0086.

3) Lorne B., Perrier F., and Avouac J-P. (1999): Streaming potential measurements 2. Relationship between electrical and hydraulic flow patterns from rock samples during deformation, J. Geophys. Res., 104, B8, 17,879 $-17,896$

4) Ozaki Y., Mikada H., Goto T. and Takekawa J. (2013): Estimation of permeability structure with self-potential inversion, SAGEEP2013, Env. \& Eng. Geophys. Soc., Expanded Abstract.

5) Ozaki Y., Mikada H., Goto T. and Takekawa J., Tsujimura M., Hachani F. (2010): Effect of heterogeneity of subsurface structure on streaming potential, $122^{\text {nd }}$ Ann Meeting, Soc. Expl. Geophys. Japan, Expanded Abstract, 173-176.

6) Revil, A. and Jardani, A. (2010): Stochastic inversion of permeability and dispersivities from time lapse self-potential measurements: A controlled sandbox study, Geophys. Res. Lett., 37, L11404.

7) Revil, A., and P. Leroy. (2004): Constitutive equations for ionic transport in porous shales: $J$. Geophys. Res., 109, B03208, doi: 10.1029/2003JB002755. 